\title{
Has the connection between polyploidy and diversification actually been tested?
}

Elizabeth A. Kellogg

Donald Danforth Plant Science Center, 975 North Warson Rd., St. Louis, MO 63132, USA

email: ekellogg@danforthcenter.org

\begin{abstract}
Many major clades of angiosperms have several whole genome duplications (polyploidization events) in their distant past, suggesting that polyploidy drives or at least permits diversification. However, data on recently diverged groups are more equivocal, finding little evidence of elevated diversification following polyploidy. The discrepancy may be attributable at least in part to methodology. Many studies use indirect methods, such as chromosome numbers, genome size, and Ks plots, to test polyploidy, although these approaches can be misleading, and often lack sufficient resolution. A direct test of diversification following polyploidy requires a sequence-based approach that traces the history of nuclear genomes rather than species. These methods identify the point of coalescence of ancestral genomes, but may be misleading about the time and thus the extent of diversification. Limitations of existing methods mean that the connection between polyploidy and diversification has not been rigorously tested and remains unknown.
\end{abstract}

\section{Paradoxical data on polyploidy and diversification}

The extensive data on polyploidy and diversification present an apparent paradox. One the one hand, every extant plant genome bears the signature of repeated rounds of polyploidization, many of which can be traced deep into phylogenetic history [1-9]. The ancient origin of such whole genome duplications is interpreted to mean that diploids do not persist in evolutionary time and that polyploidy leads to diversification. However, in studies of recent polyploids, it has been hard to find clear evidence of higher speciation or lower extinction rates in polyploids [10-13].

The idea that polyploidy leads to diversification is also consistent with studies of recent or synthetic polyploids, which generally show rapid changes in gene expression and loss of DNA. Over time many duplicate genes revert back to single copy, whereas those retained in duplicate diverge in function [14-17]. Such changes could easily provide the raw variation on which selection could act to drive speciation.

The question, "Does polyploidy lead to diversification?", is a choice between two patterns of evolution, illustrated in Figure 1. For clarity, I have used the terms auto- and allopolyploidy in their genetic, rather than taxonomic, sense, following the terminology of [18]. In the two A patterns, a polyploid forms but does not speciate further, whereas in B the polyploidization event is followed by speciation among the polyploids. All patterns can be found in nature, although the relative frequencies of 
autopolyploidy and allopolyploidy are a subject of discussion [19]. The unresolved question is whether pattern B is more common than pattern A, and if so, whether the net rate of speciation (speciation minus extinction) is higher for polyploids than that of comparable diploids. (Note that in allopolyploidy the diploid progenitors are not sister to the polyploids, and thus it is not completely clear which diploid lineages should be compared to the polyploids.) If pattern B holds, then all diploid lineages must become extinct over time, whether gradually or via a catastrophic event; otherwise we would not find genome duplications in the ancient history of all extant taxa.

I argue here that the connection between polyploidy and diversification is controversial in part because different studies use different methods, and that many of these methods do not in fact address the question directly (Table 1). I will follow the usage in the literature and use the terms diversification and speciation interchangeably. This usage ignores genetic diversification in populations even though this level will ultimately need to be integrated into discussions. Few studies have explicitly tested the relative frequencies of patterns A and B. Instead, most studies have used combinations of chromosome numbers, genome sizes, chloroplast phylogenies, and Ks plots, none of which test the question directly, and all of which have intrinsic biases. In addition, most studies have implicitly assumed an underlying model of autopolyploidy and ignored the possibility of allopolyploidy. Studies that use tree-based inference are potentially powerful in that they can test the history of genomes as laid out in Figure 1. However, this approach is still limited by gene and taxon sampling. In addition, not all studies attempt to distinguish the time of coalescence of gene trees (asterisk in the middle column of Figure 1) and diversification (double asterisk). The result is that we do not have a good estimate of either the frequency or consequences of polyploidy.

\section{Indirect methods are inconclusive}

\section{Chromosome numbers may be misleading}

Chromosome numbers have been used since the early 20th century, when polyploidy was discovered (reviewed in [20]). Since then chromosome counts have accumulated for many species [21,22]. Polyploidy is inferred if chromosome numbers are even multiples of a relatively low base number. However, determination of the diploid base number and hence ploidal level is not always straightforward. For example, Brachypodium distachyon was considered for many years to include three chromosomal races, with $n=5,10$, and 15 , interpreted as a diploid and two autopolyploids (autopolyploid pattern B). Careful cytogenetic work [23], morphometrics, and molecular phylogenies showed instead that both $n=5$, and $n=10$ were distinct diploid species, and that $n=15$ was their allopolyploid derivative [24] (allopolyploid pattern A). Such cryptic allopolyploid events (i.e., allopolyploidy masquerading as autopolyploidy) have been demonstrated in other taxa as well [12], but their frequency is unknown.

Similarly, the genus Zea (seven species) with a diploid number of $n=10$ is closely related to Tripsacum (16 species), with $n=18$. Zea is allotetraploid [25-28], and based on chromosome number alone, Tripsacum would appear to be a higher- 
order polyploid related to Zea. However, all short-read sequences from Tripsacum dactyloides map once to the Zea genome and there are no additional duplications [29]. The two genera are sisters, descended from a single allopolyploidization event [12]. Rearrangements of the genome thus must have led to both $n=18$ and $n=10$ sister lineages. Thus 23 species are derived from a single polyploidization event (allopolyploid pattern B), and chromosome numbers are uninformative about the history.

A few studies count the total number of species in a clade, and compare the number of species with high chromosome counts (presumed polyploids) with the number with low chromosome counts (presumed diploids)(e.g. [30]). However, a clade with 10 polyploids, each formed independently (pattern A, repeated 10 times), will yield the same numbers as a clade in which a single polyploid diversified into 10 species (pattern B). Thus, this approach does not address the question of polyploidy and diversification.

\section{Genome size may be unrelated to polyploidy}

A second method of estimating the incidence of polyploidy is genome size, aided by the recent availability of flow cytometry [31]. However, genome size can increase or decrease as a response to many factors unrelated to polyploidy, including transposon amplification (leading to sharp increases) [32] and repeated deletion of small pieces of DNA (leading to steady decreases) [33-35]. Genome size must then be anchored with chromosome numbers to interpret ploidal variation.

For example, genome size is inversely correlated with chromosome number in Sorghum, where Australian species have large genomes and $n=5$ and African species have smaller genomes and $n=10$ [36]. Sorghum bicolor, in the latter group, is clearly diploid [37], as are the $n=5$ species. Thus neither genome size nor chromosome number tracks ploidal level in this group. The two chromosomal groups have recently been shown to be unrelated [38] and the Australian group should be known henceforth as Sarga [39].

In another example, each of the three species of the Claytonia perfoliata complex has plants ranging from diploid to octoploid. Genome sizes for the tetraploids are approximately double those for diploids, but some hexaploid genome sizes overlap those of the octoploids [40].

\section{Chloroplast phylogenies cannot identify reticulation}

Use of chloroplast phylogenies to identify polyploids and their sister clades implies that most polyploidy is autopolyploidy. While the frequency of autopolyploidy may be underestimated [19], this is still quite a strong assumption. Only autopolyploidy will produce pairs of taxa in which a diploid clade is sister to a polyploid clade (Figure 1). In contrast, in allopolyploidy, there are potentially two diploid clades to be compared to the single polyploid clade; I do not know of any study that has explicitly considered speciation rates in multiple diploid clades as compared to their allopolyploid derivatives.

Because chloroplasts are almost always uniparentally inherited, they cannot recover reticulations caused by allopolyploidy, which will then be missed or misinterpreted. It is common to map presence or absence of polyploids on to a 
chloroplast phylogeny (e.g., $[10,11,30])$, but this oversimplifies the evolutionary history [41]. For example, chloroplast phylogenies of the woody bamboos, which are all tetraploid, have shown one or two origins of woodiness and thus one or two polyploidization events before the diversification of over 1300 species [42]. However, recent work by Triplett et al. [43] shows a complex set of at least three hybridization and allopolyploidization events. In cases where polyploidization events are missed, estimates of the numbers of species arising from any given event will be too high.

\section{Ks plots may be unable to resolve polyploidy events}

Ks plots provide a graphical method for using the synonymous differences between pairs of genes to estimate of the timing of polyploidy [5]. The absolute time of the polyploidy event is then estimated by calibrating the synonymous rate of substitution to a known date in geological history. The technique has the advantage of being applicable to a single genome and is thus excellent for data exploration. It can also be a valuable starting point for subsequent analysis; genes under the peak represent duplicates that can be used for gene tree analyses as described below.

However, despite their common use and value as a heuristic tool, Ks plots have limitations. The ability to find a peak in the frequency plot depends on there being a single event at an intermediate phylogenetic depth. If the duplication event is too recent or too ancient, the peak is hard to distinguish from the background rate [7]. The results are also sensitive to bin size. Multiple events can be hard to distinguish from each other. When comparing Ks plots between species, it can be difficult to determine if similar peaks represent the same duplication event or different, near-simultaneous, ones. For example, although Miscanthus sinensis and its close relative sugarcane (Saccharum officinarum) exhibit whole genome duplications that occurred about the same time [44], broader taxonomic sampling and analysis of gene trees shows that the two duplication events are independent [45].

\section{Direct tests of genome evolution are more robust} Genome sequences find the phylogenetic signature of polyploidy

Tracing the effects of polyploidy on diversification (i.e., distinguishing between patterns $A$ and $B$ ) requires dissecting the history of nuclear genomes rather than species, and only nuclear sequence data have the power to provide that information.

Methods for detecting polyploidy in recently diverged groups (last 20 million years) have generally used PCR-based approaches to sample the nuclear genome. In such groups close relatives of diploid genome donors are often extant, gene loss is uncommon, and nuclear gene trees appear double-labeled, as in pattern B. A gene thought to be single copy in diploids is amplified from both diploids and polyploids, and the PCR products cloned to separate out paralogous copies. The paralogues are then used to produce a gene tree in which the copies found in each polyploid are located with their respective diploid relatives [46-48]. This approach is effective but is also expensive and labor intensive. While a steady trickle of papers have used this approach to good advantage $[12,49-52]$, it has not been widely applied. A 
recent study has combined PCR with 454 sequencing [53] to bypass cloning and improve efficiency. Sequence capture has been used to dissect polyploid history in Gossypium [54], and is likely to become more widely used.

Most methods for assessing polyploidy deep in a phylogeny (e.g., the events at the base of the angiosperms or the base of the Brassicales) use whole genome sequences or transcriptomes. The methods applied in these papers implicitly assume that evolution before and after the duplication is divergent and tree like, and also assume that the diploid progenitor(s) of the polyploidy event must be extinct. In general, such studies identify pairs of paralogous genes in the genome(s) of interest, use these to find related genes from other species and construct gene trees $[4,55,56]$. If a large percentage of the gene trees identify a duplication at a particular node, a polyploidization event is inferred.

A major caveat is that most methods identify the point at which the genes in the duplicated genomes coalesce (indicated by an asterisk on the trees in the middle column of Figure 1), which is not necessarily the date of the polyploidization event $[18,55]$. If the WGD were the result of allopolyploidization, then species that branch higher could be descendants of the genome donors and might not actually share the duplication. This can be seen in diploid lineages A to E in the allopolyploid diagrams in Figure 1. The gene tree approach will map the whole genome duplication to the node with the asterisk. Even though A to E diverged after that point of coalescence, they do not share the duplication. Without sampling the genomes of all early-diverging lineages of a clade, the polyploidization event will look as though it precedes all diversification, whereas in fact the duplication would have led only to a subset of the taxa. Note that failure to distinguish the coalescence node from the diversification node could also generate the appearance of a time lag between duplication and diversification, as is often observed $[57,58]$.

Note also that a gene tree with the topology $(\mathrm{X},(\mathrm{X}, \mathrm{Y}))$ is ambiguous. It could reflect an allopolyloidization event before the divergence of $X$ and $Y$, followed by gene loss, and thus could be derived from the tree $((\mathrm{X}, \mathrm{Y})(\mathrm{X}, \mathrm{Y}))$. Alternatively, $(\mathrm{X},(\mathrm{X}, \mathrm{Y}))$ could reflect an event in which only $\mathrm{X}$ is polyploid. One diploid genome would then be donated by a now-extinct ancestor similar to $\mathrm{X}$ and the other genome donated by an ancestor similar to $\mathrm{Y}$. In this case, lineage $\mathrm{Y}$ is a persistent diploid and has no whole genome duplication in its ancestry. I know of no papers that test this possibility formally in ancient polyploids, although such tests are common in recent ones (e.g. [59]). If the latter pattern were to occur (i.e., a diploid genome donor were to persist) such ancient diploids might be quite hard to place in phylogenies. This could explain the difficulty of placing some taxa that diverged about the same time as documented polyploidy events. For example, relationships near the origin of the core eudicots have been notoriously difficult to resolve; diversification of this part of the angiosperm tree occurred at approximately the same time or just before a prominent genome triplication event [60].

All sequence-based methods face the problem of phasing, i.e., which gene represents which (sub-)genome. Correct phasing is necessary to dissect the history of genomes and becomes particularly important if genes are to be concatenated into longer sequences to amplify the phylogenetic signal. One method is by manual inspection of gene trees, although this can become somewhat circular. Referring to 
Figure 1, if paralogue $A$ is closely related to the sequence from diploid $A$ and paralogue $E$ is closely related to the sequence from diploid $E$, then we can infer that any paralogue in any gene tree close to species $A$ is in the same subgenome as paralogue $A$ and likewise that any paralogue close to species $\mathrm{E}$ is representative of subgenome $\mathrm{E}$. While this approach is not unreasonable, it biases against contradictory data.

For species with genomes that are well assembled and well annotated, using sequences of syntenic and collinear genes might help to determine the history of large blocks of chromosomes. If such genome sequences were available for both polyploids and their diploid relatives, then robust phylogenies of genomes could be assessed. However, such an approach requires a set of high quality genome sequences for species that diverged before and after the polyploidization event(s) of interest. Current genome sequences are biased toward diploids with small genomes to keep costs down and assembly easy, and few polyploids have been completed. Genome assemblies are often insufficiently complete to infer synteny. Few are anchored to a genetic map or to individual chromosomes. Thus even if this approach were to be effective the data are not yet available.

\section{Conclusion}

No method for inferring the frequency and consequences of polyploidy is fully reliable for discovering its role in diversification. What would the relative frequency of polyploidization (including hybridization and allopolyploidization) and diploid speciation have to be to produce the pattern of repeated polyploidy that we see? How long do diploid lineages persist and what sorts of patterns appear in phylogenetic trees over time? If pattern B is common, but if some of the diploid lineages persist over time, could those persistent diploids end up on long branches in phylogenies and become increasingly hard to place? In other words, could deep branches that cause problems in phylogenies be the descendants of species that did not undergo the ancient polyploidization event?

The methods commonly used to infer polyploidy are limited and some are misleading. The question of diversification following polyploidy thus remains unanswered.

\section{Acknowledgements}

I thank J. Chris Pires and Yves van de Peer for the invitation to present a talk in the Plant Genome Evolution symposium and to contribute this manuscript. I also thank the two anonymous reviewers for their constructive and helpful suggestions. Work in the Kellogg lab is supported by NSF grants DEB-1442071 and IOS-1413824.

\section{References and recommended reading}

Papers of particular interest, published within the period of review, have been highlighted as:

*of special interest 
** of outstanding interest.

1. Salse J, Bolot S, Throude M, Jouffe V, PIegu B, Quraishi UM, Calcagno T, Cooke R, Delseny $\mathrm{M}$, Feuillet $\mathrm{C}$ : Identification and characterization of shared duplications between rice and wheat provide new insight into grass genome evolution. Plant Cell 2008, 20:11-24.

2. Barker MS, Vogel H, Schranz ME: Paleopolyploidy in the Brassicales: analyses of the Cleome transcriptome elucidate the history of genome duplications in Arabidopsis and other Brassicales. Genome Biol Evol 2009, 1:391-399.

3. Van de Peer Y, Maere S, Meyer A: The evolutionary significance of ancient genome duplications. Nature Rev Genet 2009, 10:725-732.

*4. Jiao Y, Li J, Tang H, Paterson AH: Integrated syntenic and phylogenomic analyses reveal an ancient genome duplication in monocots. Plant Cell 2014, 26:2792-2802.

Using both gene trees and blocks of syntenic genes improves the ability to identify whole genome duplications.

5. Blanc G, Wolfe KH: Widespread paleopolyploidy in model plant species inferred from age distributions of duplicate genes. Plant Cell 2004, 16:1667-1678.

6. Jiao Y, Wickett N, Ayyampalayam S, Chanderbali AS, Landherr L, Ralph PE, Tomsho LP, Hu Y, Liang H, Soltis PS: Ancestral polyploidy in seed plants and angiosperms. Nature 2011, 473:97-102.

7. Cui L, Wall PK, Leebens-Mack JH, Lindsay BG, Soltis DE, Doyle JJ, Soltis PS, Carlson JE, Arumuganathan K, Barakat A, et al.: Widespread genome duplications throughout the history of flowering plants. Genome Res 2006, 16:738-749.

8. Vanneste K, Maere S, Van de Peer Y: Tangled up in two: a burst of genome duplications at the end of the Cretaceous and the consequences for plant evolution. Philos Trans R Soc Lond B Biol Sci 2014, 369.

*9. Vanneste K, Baele G, Maere S, Van de Peer Y: Analysis of 41 plant genomes supports a wave of successful genome duplications in association with the Cretaceous-Paleogene boundary. Genome Res 2014, 24:1334-1347. The authors identified pairs of genes (homoeologs) under peaks in Ks plots for species with whole genome sequences or high quality trancriptomes. These pairs were then used to identify orthologous genes in other species and to construct gene trees, which could then be calibrated and the date of the duplications estimated.

10. Wood TE, Takebayashi N, Barker MS, Mayrose I, Greenspoon PB, Rieseberg LH: The frequency of polyploid speciation in vascular plants. Proc Natl Acad Sci USA 2009, 106:13875-13879.

11. Mayrose I, Zhan SH, Rothfels CJ, Magnuson-Ford K, Barker MS, Riseberg LH, Otto SP: Recently formed polyploid plants diversify at lower rates. Science 2011, 333:1257.

**12. Estep MC, McKain MR, VelaDiaz D, Zhong J, Hodge JG, Hodkinson TR, Layton DJ, Malcomber ST, Pasquet R, Kellogg EA: Allopolyploidy, diversification, and 
the Miocene grassland expansion. Proc Natl Acad Sci USA 2014, 111:15149-15154.

A phylogeny using multiple nuclear genes shows independent allopolyploidization events leading to formation of a least a third of the species in the maize-sorghum-sugarcane group. While allopolyploidy itself is a (possibly the) major mode of speciation, diverisification after polyploidy is limited.

13. Mayrose I, Zhan SH, Rothfels CJ, Arrigo N, Barker MS, Rieseberg LH, Otto SP: Methods for studying polyploid diversification and the dead end hypothesis: a reply to Soltis et al. (2014). New Phytol 2015, 206:27-35.

14. Duarte JM, Cui L, Wall PK, Zhang Q, Zhang X, Leebens-Mack J, Ma H, Altman N, dePamphilis CW: Expression pattern shifts following duplication indicative of subfunctionalization and neofunctionalization in regulatory genes of Arabidopsis. Mol Biol Evol 2006, 23:469-478.

15. Ohno S: Evolution by gene duplication. New York: Springer; 1970.

16. Lynch M, Conery JS: The origins of genome complexity. Science 2003, 302:1401-1404.

*17. Rensing SA: Gene duplication as a driver of plant morphogenetic evolution. Curr Opin Plant Biol 2014, 17:43-48.

Whole genome duplications lead to duplications of transcription factors that regulate various aspects of plant morphology. Polyploidization thus provides the raw material for diversification.

**18. Doyle JJ, Egan AN: Dating the origins of polyploidy events. New Phytol 2010, 186:73-85.

An essential reference paper for anyone studying polyploidy. The authors clarify the distinctions between genetic and taxonomic autopolypoidy and allopolyploidy. They also highlight the importance of distinguishing between the coalescence time of the genomes of allopolyploids and the subsequent diversification time.

*19. Barker MS, Arrigo N, Baniaga AE, Li Z, Levin DA: On the relative abundance of autopolyploids and allopolyploids. New Phytol 2015.

The authors compile data from a variety of sources to estimate the frequency of auto- vs. allopolyploids in a sample of ca. 4000 species. They find that autopolyploidy may be substantially more common than previously believed.

**20. Ramsey J, Ramsey TS: Ecological studies of polyploidy in the 100 years following its discovery. Philos Trans R Soc Lond B Biol Sci 2014, 369. A thoughtful and comprehensive summary of the history of views about the role of polyploidy in speciation and ecological diversification.

21. Goldblatt P, Johnson DE (Ed): Index to plant chromosome numbers St. Louis, Missouri, USA: Missouri Botanical Garden; 1979 ....

**22. Rice A, Glick L, Abadi S, Einhorn M, Kopelman NM, Salman-Minkov A, Mayzel J, Chay O, Mayrose I: The Chromosome Counts Database (CCDB) - a community resource of plant chromosome numbers. New Phytol 2015, 206:19-26. This database is a useful tool, with an easy-to-use interface and comprehensive coverage of the literature on chromosome numbers. 
23. Hasterok R, Draper J, Jenkins G: Laying the cytotaxonomic foundations of a new model grass, Brachypodium distachyon (L.) Beauv. Chromosome Res 2004, 12:397-403.

24. Catalán P, Müller J, Hasterok R, Jenkins G, Mur LAJ, Langdon T, Betekhtin A, Siwinska D, Pimentel M, López-Alvarez D: Evolution and taxonomic split of the model grass Brachypodium distachyon. Ann Bot 2012, 109:385-405.

25. Rhodes MM: Duplicate genes in maize. Amer Nat 1951, 85:105-110.

26. Helentjaris T, Weber D, Wright $S$ : Identification of the genomic locations of duplicate nucleotide sequences in maize by analysis of restriction fragment length polymorphisms. Genetics 1988, 118:353-363.

27. Wei F, Coe E, Nelson W, Bharti AK, Engler F, Butler E, Kim H, Goicoechea JL, Chen $M$, Lee $S$, et al.: Physical and genetic structure of the maize genome reflects its complex evolutionary history. PLoS Genetics 2007, 3:e123.

28. Schnable PS, WAre D, Fulton RS, Stein JC, Wei F, Pasternak S, Liang C, Zhang J, Fulton L, Graves TA, et al.: The B73 maize genome: complexity, diversity, and dynamics. Science 2009, 326:1112-1115.

29. Chia J-M, Song C, Bradbury PJ, Costich D, deLeon N, Doebley J, Elshire RJ, Gaut B, Geller L, Glaubitz JC, et al.: Maize HapMap2 identifies extant variation from a genome in flux. Nature Genetics 2012, 44:803-807.

30. Hohmann N, Wolf EM, Lysak MA, Koch MA: A time-calibrated road map of Brassicaceae species radiation and evolutionary history. Plant Cell 2015, 10:2770-2784.

31. Leitch IJ, Bennett MD: Genome downsizing in polyploid plants. Biol J Linn Soc 2004, 82:651-663.

32. Hawkins JS, Kim H, Nason JD, Wing RA, Wendel JF: Differential lineage-specific amplification of transposable elements is responsible for genome size variation in Gossypium. Genome Res 2006, 16:1252-1261.

33. Woodhouse MR, Schnable JC, Pedersen BS, Lyons E, Lisch D, Subramianiam S, Freeling M: Following tetraploidy in maize, a short deletion mechanism removed genes preferentially from one of the two homeologs. PLoS Biology 2010, 8:e1000409.

34. Devos KM, Brown JK, Bennetzen JL: Genome size reduction through illegitimate recombination counteracts genome expansion in Arabidopsis. Genome Res 2002, 12:1075-1079.

35. Petrov D: Slow but steady: reduction of genome size through biased mutation. Plant Cell 1997, 9:1900-1901.

36. Price HJ, Dillon SL, Hodnett G, Rooney WL, Ross L, Johnston JS: Genome evolution in the genus Sorghum (Poaceae). Ann Bot 2005, 95:219-227.

37. Paterson AH, Bowers JE, Bruggmann R, Dubchak I, Grimwood J, Gundlach H, Haberer G, Hellsten U, Mitros T, Poliakov A, et al.: The Sorghum bicolor genome and the diversification of grasses. Nature 2009, 457:551-556.

*38. Hawkins JS, Ramachandran D, Henderson A, Freeman J, Carlise M, Harris A, Willison-Headley Z: Phylogenetic reconstruction using four low-copy nuclear loci strongly supports a polyphyletic origin of the genus Sorghum. Ann Bot 2015, 116:291-299. 
Sequences of low-copy nuclear loci resolve a long-standing question in the genus Sorghum, and show that the Australian and African species are unrelated. Both sets of species are diploid even though the chromosome number of the African species is double that of the Australian ones.

39. Spangler RE: Taxonomy of Sarga, Sorghum and Vacoparis (Poaceae:

Andropogoneae). Aust Syst Bot 2003, 16:279-299.

40. McIntyre PJ: Cytogeography and genome size variation in the Claytonia perfoliata (Portulacaceae) polyploid complex. Ann Bot 2012, 110:11951203.

41. Soltis DE, Segovia-Salcedo MC, Jordon-Thaden I, Majure L, Miles NM, Mavrodiev EV, Mei W, Cortez MB, Soltis PS, Gitzendanner MA: Are polyploids really evolutionary dead-ends (again)? A critical reappraisal of Mayrose et al. (2011). New Phytol 2014, 202:1105-1117.

42. Kelchner SA, Bamboo Phylogeny Group: Higher level phylogenetic relationships within the bamboos (Poaceae: Bambusoideae) based on five plastid markers. Mol Phylog Evol 2013, 67:404-413.

**43. Triplett JK, Clark LG, Fisher AE, Wen J: Independent allopolyploidization events preceded speciation in the temperate and tropical woody bamboos. New Phytol 2014, 204:66-73.

An illustration of the power of gene tree approaches to dissect the polyploid history of a large clade. Independent polyploidization events involving some of the same ancestral genomes lead to a major radiation.

44. Kim C, Wang X, Lee TH, Jakob K, Lee GJ, Paterson AH: Comparative analysis of Miscanthus and Saccharum reveals a shared whole-genome duplication but different evolutionary fates. Plant Cell 2014, 26:2420-2429.

45. Welker CAD, Souza-Chies TTd, Longhi-Wagner HM, Peichoto MD, McKain MR, Kellogg EA: Phylogenetic analysis of Saccharum s.l. (PoaceaeAndropogoneae), with emphasis on the South American species. Amer J Bot 2015, 102:248-263.

46. Mason-Gamer RJ, Burns MM, Naum M: Reticulate evolutionary history of a complex group of grasses: phylogeny of Elymus StStHH allotetraploids based on three nuclear genes. PLoS One 2010, 5:e10989.

47. Mason-Gamer RJ, Orme NL, Anderson CM: Phylogenetic analysis of North American Elymus and the monogenomic Triticeae (Poaceae) using three chloroplast DNA data sets. Genome 2002, 45:991-1002.

48. Evans RC, Campbell CS: The origin of the apple subfamily (Maloideae; Rosaceae) is clarified by DNA sequence data from duplicated GBSSI genes. Am J Bot 2002, 89:1478-1484.

49. Brassac J, Jakob SS, Blattner FR: Progenitor-derivative relationships of Hordeum polyploids (Poaceae, Triticeae) inferred from sequences of TOP06, a nuclear low-copy gene region. PLoS One 2012, 7:e33808.

50. Popp M, Oxelman B: Inferring the history of the polyploid Silene aegaea (Caryophyllaceae) using plastid and homoeologous nuclear DNA sequences. Mol Phylogenet Evol 2001, 20:474-481.

**51. Bertrand YJ, Scheen AC, Marcussen T, Pfeil BE, de Sousa F, Oxelman B: Assignment of homoeologs to parental genomes in allopolyploids for 
species tree inference, with an example from Fumaria (Papaveraceae). Syst Biol 2015, 64:448-471.

A thoughtful and effective case study disecting polyploid history in Fumaria. This paper addresses the problem of phasing, i.e. assigning sequences to ancestral diploid genomes, in part by comparing chloroplast phylogenies to the nuclear gene trees.

**52. Marcussen T, Heier L, Brysting AK, Oxelman B, Jakobsen KS: From gene trees to a dated allopolyploid network: insights from the angiosperm genus Viola (Violaceae). Syst Biol 2015, 64:84-101.

The complex history of Viola is unraveled using gene trees from low-copy nuclear loci that are then dated and used to assemble a network reflecting polyploidization events. Parsimony was used to develop a network with minimum numbers of polyploidization events and undetected lineages, and then the timing of the events was estimated using a Bayesian method.

**53. Brassac J, Blattner FR: Species-level phylogeny and polyploid relationships in Hordeum (Poaceae) inferred by next-generation sequencing and in silico cloning of multiple nuclear loci. Syst Biol 2015, 64:792-808.

The authors improve efficiency of sequencing low-copy nuclear genes by using a combination of PCR and 454 sequencing. The resulting tree topologies are sufficiently well resolved to sort out the effects of incomplete lineage sorting, hybridization and allopolyploidy.

54. Salmon A, Udall JA, Jeddeloh JA, Wendel J: Targeted capture of homoeologous coding and noncoding sequence in polyploid cotton. G3 (Bethesda) 2012, 2:921-930.

**55. Cannon SB, McKain MR, Harkess A, Nelson MN, Dash S, Deyholos MK, Peng Y, Joyce B, Stewart CN, Jr., Rolf M, et al.: Multiple polyploidy events in the early radiation of nodulating and nonnodulating legumes. Mol Biol Evol 2015, 32:193-210.

The authors use a broad taxonomic sample and comprehensive gene tree methods to place polyploidy events in the history of legumes.

*56. McKain MR, Wickett N, Zhang Y, Ayyampalayam S, McCombie WR, Chase MW, Pires JC, dePamphilis CW, Leebens-Mack J: Phylogenomic analysis of transcriptome data elucidates co-occurrence of a paleopolyploid event and the origin of bimodal karyotypes in Agavoideae (Asparagaceae). $\mathrm{Am}$ J Bot 2012, 99:397-406.

Use of extensive gene tree data places a polyploidization event in the ancestry of Yucca and Agave.

57. Schranz ME, Mohammadin S, Edger PP: Ancient whole genome duplications, novelty and diversification: the WGD radiation lag-time model. Curr Opin Plant Biol 2012, 15:147-153.

58. Tank DC, Eastman JM, Pennell MW, Soltis PS, Soltis DE, HInchliff CE, Brown JW, Sessa EB, Harmon LJ: Nested radiations and the pulse of angiosperm diversification: increased diversification rates often follow whole genome duplications. New Phytol 2015, 207:454-467. 
59. Triplett JK, Wang Y, Zhong J, Kellogg EA: Five nuclear loci resolve the polyploid history of switchgrass (Panicum virgatum $\mathrm{L}$.) and relatives. PLoS One 2012, 7:e38702.

60. Jiao Y, Leebens-Mack J, Ayyampalayam S, Bowers JE, McKain MR, McNeal J, Rolf M, Ruzicka DR, Wafula E, Wickett NJ, Wu X, Zhang Y, Wang J, Zhang Y, Carpenter EJ, Deyholos MK, Kutchan TM, Chanderbali AS, Soltis PS, Stevenson DW, McCombie R, Pires JC, Wong GK-S, Soltis DE, dePamphilis CW: A genome triplication associated with early diversification of the core eudicots. Genome Biol 13:R3.

\section{Figure caption}

Figure 1. Pattern of evolution with (B) or without (A) diversification following polyploidy. Left column shows the evolutionary history, middle column shows the pattern of gene trees assuming no gene loss or extinction, and right column gives several of the many possible gene trees that could be produced with loss of genes or incomplete sampling. Terminals with single letters are diploid; those with two letters are tetraploid, with the letter indicating the source of the genome. In the gene trees in the two right columns, the bold letter indicates the source of the gene sequence appearing in the tree and the gray letter indicates the other genome, which falls elsewhere in the tree. Asterisk indicates the point of coalescence of the ancestral diploid genomes, double asterisk indicates the node preceding diversification of the polyploids. Note that the actual poyploidization event may have occurred at any time between the coalescence point and the diversification node. Repeated independent polyploidization events involving the same parents could cause the relationships among the polyploids to appear unresolved. Patterns for auto- and allopolyploidy refer to genetic, rather than taxonomic, polyploidy, following [18]. The distinction between taxonomic and genetic polyploidy is relevant if $\mathrm{A}$ to $\mathrm{E}$ are genetically differentiated populations that are classified as members of a single species; in this case, the genetic allopolyploids would be taxonomic autopolyploids. 


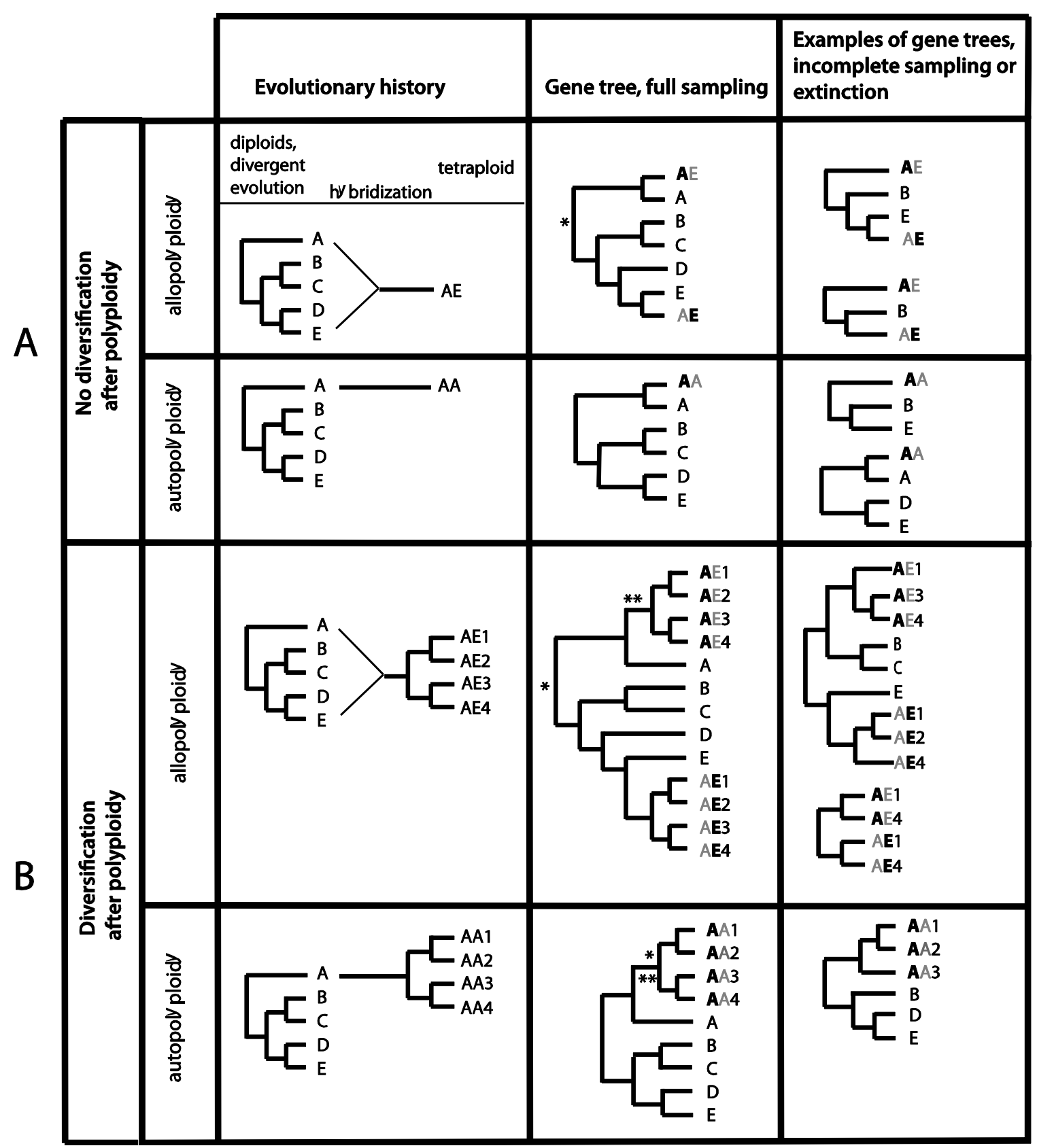

Figure 1 
Table 1. Methods used for inferring polyploidy in papers cited in this review. Papers are listed in order of occurrence in the text.

\begin{tabular}{|c|c|c|}
\hline Author and reference \# & Taxon & Method \\
\hline Salse et al. [1] & Rice, wheat (Poaceae) & Synteny \\
\hline Barker et al. [2] & Brassicales & $\begin{array}{l}\text { Ks plots, nuclear gene } \\
\text { trees }\end{array}$ \\
\hline Jiao et al. [4] & Monocots & $\begin{array}{l}\text { Synteny, nuclear gene } \\
\text { trees }\end{array}$ \\
\hline Blanc and Wolfe [5] & Various angiosperms & Ks plots \\
\hline Jiao et al. [6] & Seed plants & Nuclear gene trees \\
\hline Cui et al. [7] & Angiosperms & Ks plots \\
\hline Vanneste et al. [9] & Land plants & $\begin{array}{l}\text { Ks plots, nuclear gene } \\
\text { trees }\end{array}$ \\
\hline Wood et al. [10] & Vascular plants & Chromosome numbers \\
\hline Mayrose et al. [11] & Vascular plants & Chromosome numbers \\
\hline Estep et al. [12] & Andropogoneae (Poaceae) & Nuclear gene trees \\
\hline Barker et al. [19] & Angiosperms & Chromosome numbers \\
\hline Hasterok et al. [23] & Brachypodium (Poaceae) & Cytogenetics \\
\hline Catalán et al. [24] & Brachypodium (Poaceae) & $\begin{array}{l}\text { Nuclear gene trees, } \\
\text { cytogenetics }\end{array}$ \\
\hline Rhodes [25] & Maize (Poaceae) & Genetics, linkage mapping \\
\hline Helentjaris et al. [26] & Maize (Poaceae) & Linkage mapping, RFLP \\
\hline Wei et al. [27] & Maize (Poaceae) & synteny \\
\hline Schnable et al. [28] & Maize (Poaceae) & synteny \\
\hline Chia et al. [29] & $\begin{array}{l}\text { Maize, Tripsacum } \\
\text { (Poaceae) }\end{array}$ & synteny \\
\hline Hohmann et al. [30] & Brassicaceae & Chromosome numbers \\
\hline Price et al. [36] & Sorghum (Poaceae) & $\begin{array}{l}\text { Chromosome numbers, } \\
\text { genome size }\end{array}$ \\
\hline Hawkins et al. [38] & Sorghum (Poaceae) & Nuclear gene trees \\
\hline McIntyre et al. [40] & Claytonia (Montiaceae) & Chromosome numbers \\
\hline Triplett et al. [43] & Bambusoideae (Poaceae) & Nuclear gene trees \\
\hline Kim et al. [44] & $\begin{array}{l}\text { Miscanthus, sugar cane } \\
\text { (Poaceae) }\end{array}$ & Ks plots \\
\hline Welker et al. [45] & Saccharum (Poaceae) & Nuclear gene trees \\
\hline $\begin{array}{l}\text { Mason-Gamer et al. [46, } \\
\text { 47] }\end{array}$ & Elymus (Poaceae) & Nuclear gene trees \\
\hline Evans and Campbell [48] & Rosaceae (Maloideae) & Nuclear gene trees \\
\hline Brassac et al. $[49,53]$ & Hordeum (Poaceae) & Nuclear gene trees \\
\hline Popp and Oxelman [50] & Silene (Caryophyllaceae) & Nuclear gene trees \\
\hline Bertrand et al. [51] & Fumaria (Papaveraceae) & Nuclear gene trees \\
\hline Marcussen et al. [52] & Viola (Violaceae) & Nuclear gene trees \\
\hline Salmon et al. [54] & Gossypium (Malvaceae) & Nuclear gene trees \\
\hline
\end{tabular}




\begin{tabular}{|l|l|l|}
\hline Cannon et al. [55] & Fabaceae & Nuclear gene trees \\
\hline McKain et al. [56] & Agavoideae (Asparagaceae) & Nuclear gene trees \\
\hline Schranz et al. [57] & Various angiosperms & Mapping on existing trees, \\
\hline Tank et al. [58] & Angiosperms & $\begin{array}{l}\text { Mapping on chloroplast } \\
\text { phylogeny }\end{array}$ \\
\hline Triplett et al. [59] & Panicum (Poaceae) & Nuclear gene trees \\
\hline Jiao et al. [60] & Eudicots & Nuclear gene trees \\
\hline
\end{tabular}

